\title{
Can centralised care of complex laparoscopic procedures prevent urinary tract injuries?
}

\author{
H. Morsi • G. Phillips
}

Received: 2 November 2008 / Accepted: 29 December 2008 / Published online: 15 January 2009

(C) Springer-Verlag 2009

\begin{abstract}
Centralised care of complex laparoscopic procedures offers expertise and multidisciplinary care. The objective was to identify if centralised care makes urinary tract injuries less likely or avoidable. This Retrospective Audit was performed at a Tertiary Referral Centre for Advanced Laparoscopic Surgery in North East England. The incidence of injury to bladder/ureter, time of diagnosis, instrument, location, side and mode of repair were evaluated in 105 consecutive complex laparoscopic procedures. Injuries were identified in three $(2.8 \%)$ cases. There was one bladder injury which was unavoidable. The bladder dome was opened to allow excision of bladder endometriosis. There were two ureter injuries. The first injury involved the ureter being locked in a vaginal vault stitch. The second injury had stage IV endometriosis with peri-ureteric endometriosis where the anatomy was distorted, with medial displacement and kinking of the ureter secondary to fibrosis at the level of the ureter crossing below the uterine artery, with resultant accidental transection of the ureter close to the uterine artery. The first ureter injury was not a laparoscopic injury but due to vaginal vault closure. Arguably, vault closure in any vaginal hysterectomy could carry the same theoretical risk. The only direct laparoscopic injury was the ureteral
\end{abstract}

H. Morsi $(\bowtie)$

Obstetrics \& Gynaecology Department, Russell's Hall Hospital, Dudley Group of Hospitals NHS Foundation Trust,

Pensnett Road, Dudley,

West Midlands DY1 2HQ, UK

e-mail: hassan17870@doctors.org.uk

G. Phillips

Obstetrics \& Gynaecology Department,

The James Cook University Hospital,

Marton Road,

Middlesbrough TS4 3BW, UK transection. Such cases present a challenge due to a higher chance of anatomical distortion and predisposition to urinary tract injury. Noteworthy here is the fact that the ureter injury occurred where there was probable distortion of the anatomy, due to endometriosis, of the ureter at the level of the uterine artery. These cases are tackled by experienced laparoscopic surgeons in tertiary centres, yet injuries still occur. Is it possible then that those injuries represent a minimum unavoidable injury rate, and are they injuries or in fact unavoidable consequences of such inherently dangerous and difficult surgery?

Keywords Complex laparoscopic procedures · Advanced laparoscopic surgery · Complications · Injury · Ureter · Bladder

\section{Introduction}

Gynaecologic laparoscopic surgery (GLS) is becoming more popular. A prime concern with GLS is its safety and the expertise needed to undertake it. There is still the perception that many complications of GLS can or could have been prevented by open surgery. It is unfortunate that the main drive for this perception is historical concerns rather than closer scrutiny and evidence-based analysis.

The urinary tract is vulnerable to injury because of its subtle appearance, its retroperitoneal nature and its long course from the renal pelvis to the bladder. There is a wide variation in reported rates of injury to the urinary tract as a result of GLS [1], mainly due to differences in study design, surgeons' experience, technique and case complexity.

Centralised care of complex laparoscopic procedures offers the advantages of established advanced laparoscopic 
skills, advanced multidisciplinary care and an ideal theatre setup. It has been shown that the risk of complications in GLS is inversely proportionate to the experience of the operator [2]. The theatre setup and hospital structure must be capable of adapting to efficient practice of laparoscopic surgery. This keeps risks of complications to a minimum [3] and reduces cost [4]. It is thus reasonable to assume that established operators at minimal access surgery centres already have the experience and the setup to provide safe, specialised advanced laparoscopic surgery.

The aim was to identify the risk of urinary tract injury in complex laparoscopic procedures performed by skilled laparoscopic operators in an advanced laparoscopy centre, and to compare this centre's practice to published parameters for prevention/identification of urinary tract injury [5].

\section{Methods}

All the procedures were performed at the James Cook University Hospital (JCUH) in Middlesbrough. This is a large teaching hospital with a well-known (nationally and internationally) referral centre for advanced laparoscopic surgery as well as a regional training centre for minimal access surgery. Until the year 2000, the JCUH was the venue of the 'The WEL Foundation', a multidisciplinary renowned centre for treatment of endometriosis, which was a registered charity whose aim was to provide safe endoscopic surgery for women.

The procedures were identified retrospectively, using the codes of advanced laparoscopic procedures, by searching the operating theatre database. One hundred and five operative procedures were examined. All procedures were performed by experienced laparoscopic surgeons. The notes were examined individually. The individual counts of each procedure are shown in Table 1.

Laparoscopic entry and operative techniques were performed using established published techniques [6-9]. All the operations were performed for benign pathology (except for one case with primary peritoneal carcinoma who received four cycles of chemotherapy preoperatively

Table 1 Distribution of procedures

\begin{tabular}{lc}
\hline $\begin{array}{l}\text { Procedure } \\
\text { total } n=105)\end{array}$ & $\begin{array}{l}\text { Count }(\%) \\
\text { total=105 }\end{array}$ \\
\hline $\begin{array}{l}\text { Laparoscopic-assisted Doderlein } \\
\text { vaginal hysterectomy (LADVH) }\end{array}$ & $53(50.5 \%)$ \\
$\begin{array}{l}\text { Radical/laparoscopic excision } \\
\text { of endometriosis (R/LEE) }\end{array}$ & $39(37.1 \%)$ \\
$\begin{array}{l}\text { Total laparoscopic hysterectomy (TLH) } \\
\text { Laparoscopic adhesiolysis/laparoscopic } \\
\text { salpingoophorectomy }\end{array}$ & $4(3.8 \%)$ \\
\hline
\end{tabular}

followed by laparoscopic bilateral salpingoophorectomy). One case had laparoscopic-assisted Doderlein vaginal hysterectomy (LADVH) for atypical endometrial hyperplasia and was then found to have FIGO 1B G2 endometrioid adenocarcinoma of the uterus.

The vast majority of the procedures was performed by one operator $(93.3 \%), 1.9 \%$ for each of three other operators and $0.9 \%$ for one operator. The patients were assessed in terms of surgical risk in view of risk factors; previous surgery, known endometriosis (previous confirmation by histology), benign ovarian masses, fibroids, pelvic inflammatory disease, previous irradiation or known urogenital congenital anomalies (one case underwent LADVH and was known to have uterus didelphys with a single right kidney with a history of partial nephrectomy for a right duplex system). The documentation during the clinic consultation was assessed in terms of discussion of planned surgery, alternatives offered, risks of surgery, leaflets provided and GP (general practitioner) letter documentation. The operative notes were then analysed for safety rules for entry as per the Middlesbrough consensus document, meticulous technique, documentation of difficulties and of identification of the ureters at the start, during and at the end of the procedure, method of ureter identification, time of diagnosis of injury, side, type, site of injury, causative instrument, multidisciplinary input, mode and route of repair, follow-up and sequelae. Where necessary, perioperative illuminated ureteric stents were used with cystoscopy with or without indigo carmine dye, which was included in the preoperative discussion and consenting process.

\section{Results}

Table 2 shows all the cases needing perioperative ureteric identification. Almost $88 \%$ of the procedures had one or more pre-existing risk factors (Table 3), either endometriosis or adhesions from chronic pelvic inflammatory disease (five cases), previous pelvic surgery (examples include caesarean section, CLAM cystoplasty, colposuspension, abdominal hysterectomy, previous midline laparotomy for left borderline mucinous ovarian mass) or from advanced endometriosis, large $(>5 \mathrm{~cm})$ adherent ovarian endometriomas, benign ovarian masses or uterine fibroids. In $93 \%$ of cases, the ureters were identified visually or by an invasive means. There were eight cases where the ureters were not identified or documented presumably due to the surgeon being relatively reassured that the pathology was away from clearly visible, peristaltic ureters. Interestingly, in those cases, there were two ureteric injuries details of which are described below. Eight cases had no form of bladder integrity 
Table 2 This table shows the details of all the 29 cases needing preoperative or intraoperative ureteric stenting, ureteroscopy or retrograde ureterogram

\begin{tabular}{|c|c|c|c|}
\hline & Risk factors & Operation & Injury \\
\hline Case 1 & Endometriosis IV, ovarian mass & $\begin{array}{l}\text { RLEE, large endometriomas, adherent rectum, } \\
\text { bilateral stents }\end{array}$ & No \\
\hline Case 2 & $\begin{array}{l}\text { Endometriosis IV, previous left } \\
\text { nephrectomy, left ureterectomy, } \\
\text { LSO, segmental sigmoid resection }\end{array}$ & LADVH, RSO, adhesiolysis, right stent & No \\
\hline Case 3 & Endometriosis I & Treatment of endometriosis, left stent & No \\
\hline Case 4 & Caesarean section & LADVH, LSO, right stent & No \\
\hline Case 5 & Fibroid & $\begin{array}{l}\text { LADVH (no dye from left ureter, } \\
\text { paste-like material dislodged } \\
\text { by ureter guide, bilateral retrograde } \\
\text { ureterogram, ureters normal on USS, IVP, CT scan) }\end{array}$ & No \\
\hline Case $6,18,22$ & Endometriosis II-IV & LEE, left/bilateral stents & No \\
\hline Case 7 & $\begin{array}{l}\text { Endometriosis IV, fibroid, } \\
\text { previous surgery }\end{array}$ & $\begin{array}{l}\text { RLEE, left stent, left ureterolysis, enterolysis, } \\
\text { LSO, Mirena insertion }\end{array}$ & No \\
\hline Case 8 & Endometriosis I/II, previous surgery & LAVDH, bilateral stents, LEE & No \\
\hline Case 9 & Endometriosis II & $\begin{array}{l}\text { Ablation of endometriosis, left stent, hysteroscopy, } \\
\text { Fenton's }\end{array}$ & No \\
\hline Case 10,11 & Endometriosis IV & $\begin{array}{l}\text { RLEE, bilateral stents, left ovarian cystectomy } \\
\text { (case 10), dye test }\end{array}$ & No \\
\hline Case 12 & Endometriosis, previous surgery & $\begin{array}{l}\text { Extensive adhesiolysis, trachelectomy, } \\
\text { ureteroscopy }\end{array}$ & No \\
\hline Case 13 & Endometriosis & Adhesiolysis, LEE, Dye test, Hysteroscopy & No \\
\hline Case 14 & $\begin{array}{l}\text { Endometriosis, } \\
\text { pelvic inflammatory disease }\end{array}$ & $\begin{array}{l}\text { LAVDH, LSO, excision of bladder } \\
\text { endometriosis, check cystoscopy+left } \\
\text { retrograde rigid ureteroscopy }\end{array}$ & Yes (bladder) \\
\hline Case 15 & Endometriosis & $\begin{array}{l}\text { LEE, adhesiolysis, bilateral ureterolysis, } \\
\text { bilateral stents }\end{array}$ & No \\
\hline Case 16 & Endometriosis III & LEE, hysteroscopy, bilateral stents & No \\
\hline Case 17 & $\begin{array}{l}\text { Endometriosis IV, } \\
\text { rectovaginal endometriosis, } \\
\text { ovarian mass }\end{array}$ & $\begin{array}{l}\text { RLEE, LADVH, BSO, bilateral stents, } \\
\text { ureterolysis }\end{array}$ & No \\
\hline Case 19 & Endometriosis, previous surgery & LADVH, RSO, right stent & No \\
\hline Case 20 & $\begin{array}{l}\text { Previous radical hysterectomy } \\
\text { for } 1 \mathrm{~B} 1 \text { cervical cancer and lymphadenectomy }\end{array}$ & $\begin{array}{l}\text { Adhesiolysis, left oophorectomy, } \\
\text { bilateral stents }\end{array}$ & No \\
\hline Case 21 & Endometriosis II & LEE, dye test, bilateral stents & No \\
\hline Case 23 & Endometriosis IV & RLEE, bilateral stents & No \\
\hline Case 24 & Endometriosis IV & RLEE, LADVH, BSO, bilateral stents & No \\
\hline Case 25 & Endometriosis, fibroid & $\begin{array}{l}\text { Ablation of endometriosis, LSO, } \\
\text { hysteroscopy, left stent }\end{array}$ & No \\
\hline Case 26 & Endometriosis IV & RLEE, LADVH, BSO, bilateral stents & No \\
\hline Case 27 & Endometriosis IV & $\begin{array}{l}\text { RLEE, excision/ablation of endometriomas, } \\
\text { bilateral stents }\end{array}$ & No \\
\hline Case 28 & Endometriosis & $\begin{array}{l}\text { TLH, RSO, excision of endometriosis, } \\
\text { repair of right ureter (JJ stent) }\end{array}$ & Yes (ureter) \\
\hline Case 29 & $\begin{array}{l}\text { Fibroid, left ovarian } \\
\text { fibroma } 9 \mathrm{~cm}\end{array}$ & $\begin{array}{l}\text { LADVH, LSO, left JJ stent, } \\
\text { retrograde ureterogram }\end{array}$ & Yes (ureter) \\
\hline
\end{tabular}

LSO left salpingoophorectomy, $R S O$ right salpingoophorectomy, $B S O$ bilateral salpingoophorectomy, USS ultrasound scan, $L A D V H$ laparoscopicassisted Doderlein vaginal hysterectomy, $T L H$ total laparoscopic hysterectomy, $L E E$ laparoscopic excision of endometriosis, $R L E E$ radical laparoscopic excision of endometriosis

check most likely due to uneventful surgery and a reassured surgeon. There were no injuries in this group. Details of the procedures with bladder injury and ureteric injuries are as follows:

\section{Bladder injury}

This case was undergoing LADVH and LSO with excision of bladder endometriosis. This patient was known to have 
Table 3 Adherence to recommendations to prevent/diagnose urinary tract injury

\begin{tabular}{|c|c|c|}
\hline & Number/105 & $\%$ \\
\hline \multicolumn{3}{|l|}{ Risk factors (RFs) } \\
\hline No RF & 13 & 12.4 \\
\hline $1 \mathrm{RF}$ & 50 & 47.6 \\
\hline 2 RFs & 36 & 34.3 \\
\hline $3 \mathrm{RFs}$ & 6 & 5.7 \\
\hline $\begin{array}{l}\text { Clinic documentation } \\
\text { adequate (and leaflets)? }\end{array}$ & 105 & 100 \\
\hline Difficulties documented? & 105 & 100 \\
\hline Meticulous technique? & 105 & 100 \\
\hline \multicolumn{3}{|c|}{ Ureter identification: visual/otherwise } \\
\hline Yes & 97 & 92.4 \\
\hline $\begin{array}{l}\text { No (includes not } \\
\text { documented) }\end{array}$ & 8 (2 ureteric injuries) & 7.6 \\
\hline \multicolumn{3}{|c|}{ Cystoscopy + ureteric stents/ureterogram/ureteroscopy } \\
\hline Yes & 29 & 27.6 \\
\hline No & 76 & 72.4 \\
\hline \multicolumn{3}{|l|}{ Cystoscopy + indigo carmine } \\
\hline Yes & 60 & 57.1 \\
\hline No & 45 & 42.9 \\
\hline Cystoscopy alone & 8 & 7.6 \\
\hline $\begin{array}{l}\text { Bladder not checked } \\
\text { by any means }\end{array}$ & 8 & 7.6 \\
\hline Injury (total): & 3 & 2.8 \\
\hline Bladder & 1 (bladder endometriosis) & 0.9 \\
\hline Ureter & $\begin{array}{l}2 \text { (vault stitch } / 50 \% \\
\text { transection) }\end{array}$ & 1.9 \\
\hline
\end{tabular}

endometriosis and pelvic inflammatory disease from previous laparoscopies. The patient was counselled appropriately in the clinic. The endometriotic nodule was noted to involve the bladder wall. An intentional cystotomy was performed to allow complete excision of this bladder nodule. It was repaired laparoscopically with the urological surgeon in attendance. The urological surgeon then performed check cystoscopy to verify the integrity of the repair with a left retrograde rigid ureteroscopy which revealed no abnormalities. This patient has suffered no long-term morbidity.

\section{Ureteric injury: case 1}

This case was undergoing TLH, RSO and LEE. This patient was nulliparous with narrow vaginal access and known to have stage IV endometriosis. Preoperative counselling was adequate. In the operative notes, the surgeon wrote; 'there was thick nodular endometriosis around the right ureter pulling it medially'. The injury of the right ureter was noted immediately and was caused by the bipolar diathermy and scissors leading to $50 \%$ transection. It was erroneously believed to be a blood vessel as the injury of the right ureter was close to the site of the right uterine artery. The urology team were asked to attend who inserted a JJ-shaped ureteric stent and laparoscopic repair of the right ureter followed. A $10-\mathrm{mm}$ portion of the coagulated ureter ends (till healthy ureter) was excised and tension-free reanastomosis of healthy ureter ends followed using full thickness $3 / 0$ polyglactin sutures. An intravenous urogram 10 days later showed no abnormalities. The stent was removed at 8 weeks and intravenous pyelograms (IVP) at 6 and 12 months were normal. To date, this patient has suffered no long-term morbidity.

Ureteric injury: case 2

This case was undergoing LADVH and LSO. This patient was known to have a fibroid uterus and a 9-cm left ovarian fibroma. Preoperative counselling was adequate. The ureters were identified visually transperitoneally at the start of the operation. At the end of the operation, the ureter integrity was checked by cystoscopy and indigo carmine. It was then noted that there was no dye coming from the left ureteric orifice. The urology team were called who then performed a retrograde ureterogram. The left ureter was blocked possibly due to a uterine pedicle or vaginal vault stitch that had perforated the ureter and locked it. A JJshaped stent was placed and the stitch released. Eight weeks later, a retrograde ureterogram revealed no problems and the left ureteric stent was removed. Table 4 shows a summary of the cases of ureteric injury.

\section{Discussion}

There is now accumulating evidence for the comparable safety of GLS. A recent publication by the National Institute for Health and Clinical Excellence (NICE) institute on laparoscopic hysterectomy [10] has said that there is now adequate evidence to support the safety, efficacy of laparoscopic techniques for hysterectomy. It has been shown in a meta-analysis that GLS is not inherently dangerous for patients presenting with benign gynaecological pathologies and that the complication risk should no longer be advanced as an argument against laparoscopic surgery [11].

The total rate of injury to the urinary tract in this study was $2.8 \%$. If considered separately, the risk of bladder injury was $0.9 \%$ and that of ureter injury was $1.9 \%$. These rates are somewhat higher than published figures (Table 5). We, however, have to take into consideration the complexity of the cases being studied, most of whom have been referred to this tertiary centre following unsuccessful treatment elsewhere and their pre-existing risk factors. They are therefore more 'challenging' cases. Ou et al. 
Table 4 Details of the two cases with ureteric injury

\begin{tabular}{|c|c|c|}
\hline & \multicolumn{2}{|l|}{ Ureteric injury cases } \\
\hline & Case 1 & Case 2 \\
\hline Surgeon & Senior & Senior \\
\hline Procedure & LADVH, LSO & $\begin{array}{l}\text { TLH, RSO, RLEE } \\
\text { stage IV }\end{array}$ \\
\hline Risk factors & $\begin{array}{l}\text { Fibroid, 9-cm } \\
\text { ovarian fibroma }\end{array}$ & Stage IV endometriosis \\
\hline Diagnosis & $\begin{array}{l}\text { Intraoperative; suspected } \\
\text { at check cystoscopy }\end{array}$ & $\begin{array}{l}\text { Intraoperative: transected, } \\
\text { ?? blood vessel }\end{array}$ \\
\hline Side & Left & Right \\
\hline Type & $\begin{array}{l}\text { Perforation thru } \\
\text { and thru/locking }\end{array}$ & $50 \%$ transaction \\
\hline Site & $\begin{array}{l}\text { Distal ureter close } \\
\text { to left vaginal vault }\end{array}$ & $\begin{array}{l}\text { Close to right uterine } \\
\text { artery, thick nodular } \\
\text { endometriosis }\end{array}$ \\
\hline Instrument & Vaginal vault stitch & Bipolar diathermy, scissors \\
\hline Urology input & Yes (intraoperative) & Yes (intraoperative) \\
\hline $\begin{array}{l}\text { Mode of } \\
\text { repair }\end{array}$ & $\begin{array}{l}\text { Retrograde ureterogram, } \\
\text { left JJ stent, vaginal } \\
\text { vault stitch release }\end{array}$ & $\begin{array}{l}\text { Right JJ ureteric stent, full } \\
\text { thickness repair of ureter, } \\
\text { excision, tension-free } \\
\text { reanastomosis }\end{array}$ \\
\hline $\begin{array}{l}\text { Route of } \\
\text { repair }\end{array}$ & Vaginal & Laparoscopic \\
\hline Follow-up & 8 weeks & $\begin{array}{l}10 \text { days, } 8 \text { weeks, } \\
6 \text { months, } 12 \text { months }\end{array}$ \\
\hline $\begin{array}{l}\text { Investigations/ } \\
\text { sequelae }\end{array}$ & $\begin{array}{l}\text { Cystoscopy, stent } \\
\text { removal, left retrograde } \\
\text { ureterogram/none }\end{array}$ & $\begin{array}{l}\text { IVU, stent removal, } \\
\text { renogram/none }\end{array}$ \\
\hline
\end{tabular}

[12] questioned the existence of a learning curve as they could not find a reduction in operating time in 839 LAVHs undertaken by four surgeons. The explanation for that was that as the surgeon accrues experience, more difficult cases are undertaken. The results of an American survey suggested that complication rates increase with more complex laparoscopic procedures [13]. Furthermore, a noteworthy fact is that the ureter injured in Dorderlein's hysterectomy was associated with distortion of the pelvic anatomy and probable kinking and displacement of the ureter at the uterine vessel complex. Therefore, based on the above arguments, those cases were more challenging and more prone to injury, despite being operated upon by expert laparoscopic surgeons.

It could be argued that the bladder hole was unavoidable if complete excision of the bladder endometriotic nodule was to be achieved. The alternatives were to avoid surgery or to avoid removing the nodule or to try and remove it without causing a bladder hole. Certainly, avoidance of surgery or leaving the nodule behind would not have treated the patient's cyclical hematuria. A similar challenge would have been encountered if this procedure was done by open surgery, with the surgeon losing the added benefit of magnification and clear views of organs and anatomical landmarks with laparoscopy compared to the crude, gross views offered by laparotomy. Relevant disadvantages of laparoscopy in this case are the loss of depth perception and tactile sensation. Nevertheless, the bladder hole was detected immediately and repaired laparoscopically with no added long-term morbidity. A further benefit of this surgery being done in this tertiary centre is the ability to repair this complication laparoscopically.

Both ureters were injured in their distal segment, one on the right side and one on the left side. One case of ureteric injury had stage IV endometriosis. It is known that $38 \%$ of ureter injuries occur during treatment of endometriosis [14]. There was clear documentation of the presence of thick nodular endometriosis around the right ureter causing anatomical distortion and pulling the ureter medially. Studies have indicated that remaining strictly within the boundaries of the lateral edge of the uterus medially and a sectioned uterine artery laterally would make injury of the ureter theoretically impossible as it is located outside the uterine artery [5]. In this instance, however, the ureter was

Table 5 Urinary tract complications with laparoscopic surgery reported in different studies

\begin{tabular}{|c|c|c|c|}
\hline Study & $\begin{array}{l}\text { Bladder } \\
\text { injury \% }\end{array}$ & $\begin{array}{l}\text { Ureter } \\
\text { injury \% }\end{array}$ & Overall \% \\
\hline Baggish et al. $1992^{1}$ & - & - & 4.8 \\
\hline Liu and Reich $1994^{2}$ & - & 0.19 & 1.4 \\
\hline $\begin{array}{l}\text { Garry and Phillips } \\
1995^{3}\end{array}$ & 1.1 & 0.3 & 1.4 \\
\hline Saidi et al. $1996 \mathrm{a}^{4}$ & 0.84 & - & - \\
\hline Saidi et al. $1996 b^{5}$ & - & 2.9 & - \\
\hline Harris et al. $1996^{6}$ & - & - & 1.6 \\
\hline O'Shea et al. $1996^{7}$ & - & - & 2.4 \\
\hline Harkki-Siren $1997^{8}$ & - & 1.29 & - \\
\hline Hulka et al. $1997^{9}$ & 1 & 0.3 & 1.3 \\
\hline Meikle et al. $1997^{10}$ & $\begin{array}{r}1.0-1.8(\mathrm{vv} \\
\text { fistula } 0.2)\end{array}$ & $0.3-0.4$ & $1.3-2.2$ \\
\hline Garry $1998^{11}$ & - & 2 & - \\
\hline $\begin{array}{l}\text { Tamussino et al. } \\
1998^{12}\end{array}$ & - & 4.3 & - \\
\hline Harkki-Siren $1998^{13}$ & 0.22 & 1.39 & 1.61 \\
\hline Makinen et al. $2001^{14}$ & - & 1.1 & - \\
\hline Johnston et al. $2003^{15}$ & 0.16 & 0.16 & 0.32 \\
\hline \multirow[t]{2}{*}{ Garry et al. $2004^{16}$} & 2.1 & 0.9 & $\begin{array}{c}3.0 \text { ( } \mathrm{LH} \text { in } \\
\mathrm{AH} \text { arm) }\end{array}$ \\
\hline & 0.9 & 0.3 & $\begin{array}{c}1.2 \text { ( } \mathrm{LH} \text { in } \\
\mathrm{VH} \text { arm) }\end{array}$ \\
\hline Jha et al. $2004^{17}$ & - & $1.39-6.0$ & - \\
\hline $\begin{array}{l}\text { McMaster-Fay and } \\
\text { Jones } 2006^{18}\end{array}$ & - & 0.39 & - \\
\hline Leonard et al. $2007^{19}$ & - & 0.3 & - \\
\hline NICE $2007^{20}$ & $\begin{array}{l}0.4(\mathrm{vv} \text { fistula } \\
0.2)\end{array}$ & 1.3 & 1.7 \\
\hline Range & $0.16-2.1$ & $0.16-6.0$ & $0.32-8.1$ \\
\hline This study & 0.9 & 1.9 & 2.8 \\
\hline
\end{tabular}


pulled medially, away from its normal position. Indeed, it was mistaken for a blood vessel and was injured close to the uterine artery. The injury, as documented, was $50 \%$ transection using bipolar diathermy and scissors. The injury was identified immediately and repaired laparoscopically with the urology team. The immediate identification of the injury, multidisciplinary input and laparoscopic repair all help reduce the impact of the injury on morbidity, recovery time, kidney and ureter function.

Using a retrospective critical analysis of this complication, it is possible that preoperative ureter stent in this particular case might have prevented the ureter injury. The policy in this unit regarding usage of ureteric stents is that of selective use. This depends on the ability to visualise, dissect the ureter, the proximity of the disease to the ureter or if there is significant pelvic sidewall disease at the time of the procedure. Therefore, it is usually a retrospective decision during the laparoscopy. In this case, a problem in ureteric identification was not anticipated and therefore this complication was not expected. The ureter was completely surrounded by disease and its location was distorted as it was pulled medially at the level of the uterine artery. The authors feel that in this particular case, had the ureter been identified, safe removal of disease would have involved leaving residual disease due to the extensive nature of this disease at this critical area. This selective policy of stent usage is based on the surgeon's expertise, judgement at the time and it is a process that is undergoing continuous modification and review depending on complication rates.

From the authors' point of view, this complication shows that the judgement made at the time was incorrect and that preoperative stent usage in that particular instance might have averted the injury. The learning point for the authors is to have a lower threshold for stent usage in the future.

The other ureteric injury was completely unexpected as the procedure was straightforward. It is possible that the ureteric anatomy was distorted by the fibroid uterus and the ovarian fibroma. The left ureter injury was suspected when indigo carmine dye failed to show at the left ureteric orifice at the time of cystocopy. The left ureter was locked by a uterine pedicle or vaginal vault stitch. Arguably, this complication is not a direct laparoscopic injury and, theoretically speaking, could occur in any vaginal hysterectomy. Complications of laparoscopic surgery have been classified as either approach or technique related [15]; this complication does not fit in either category. Had it not been for the check cystoscopy and indigo carmine at the end, this complication would have been missed with disastrous consequences.

The major limitation of this study is that it is retrospective in nature with underestimation of the potential risk (reporting bias) due to subclinical injury or inadvertent omission if the identification mechanism fails. Furthermore, the sample size was relatively small. Extrapolation of the findings in this study would be difficult for other units as the caseload in this study represents complicated cases referred to skilled laparoscopic surgeons for tertiary care.

\section{Conclusion}

Injuries to the urinary tract, albeit some cases have anatomical distortion with increased likelihood of urinary tract injury, still occur despite skilled laparoscopic surgeons undertaking those advanced laparoscopic procedures in a well-established theatre setting. It has already been said that surgery adjacent to the ureter will continue to result in occasional iatrogenic injury [16]. Is it then fair to say that those injuries represent a minimum unavoidable injury rate, and are they injuries or in fact unavoidable consequences of such inherently dangerous surgery? The important issue primarily should be the early recognition and management of urinary tract injuries, yet undoubtedly avoidance, if at all possible, remains the most attractive option.

Acknowledgements The authors are grateful to the theatre database team and the central clinical audit team who provided valuable help in case identification and patients' notes retrieval.

Disclosure of interests None declared

Contribution to authorship Hassan Morsi designed the study, collected and analysed the data and prepared the draft paper. Graham Phillips reviewed the paper and provided corrections until the final draft was achieved.

Ethics approval This was a retrospective audit conducted, within the Trust's Clinical Audit program, with Trust approval through the Audit Lead and the Clinical Audit department and registered (audit design and results) on the Trust's Clinical Audit Database. In view of this not being within the confines of research, independent research ethics committee approval was not sought.

Funding None

Declaration The abstract of this paper has been presented as an oral presentation at the 7 th annual congress of the RCOG in Montreal Canada on 18.09.2008

\section{References}

1. Härkki-Sirén P (1999) Laparoscopic hysterectomy outcome and complications in Finland. PhD thesis (academic dissertation). Helsinki, University of Helsinki 
2. Chapron C, Querleu D, Bruhat M-A, Madelenat P, Fernandez H, Pierre F et al (1998) Surgical complications of diagnostic and operative gynaecological laparoscopy: a series of 29,966 cases. Hum Reprod 13:867-872

3. Pierre F, de Poncheville L, Chapron C (1998) Laparoscopic surgery complication rate should be evaluated in an unselected population of operators: a French survey on gynaecological laparoscopy. Hum Reprod 13:1761

4. Bachmann GA, Trattler B, Ko T, Tweddel G (1998) Operational improvement of gynecologic laparoscopic operating room services: an internal review. Obstet Gynecol 92:142-144

5. Leonard F, Fotso A, Borghese B, Chopin N, Foulot H, Chapron C (2007) Ureteral complications from laparoscopic hysterectomy indicated for benign uterine pathologies: a 13-year experience in a continuous series of 1300 patients. Hum Reprod 22(7):20062011

6. Garry R (1999) A consensus document concerning laparoscopic entry techniques: Middlesbrough. Gynaecol Endosc 8:403-406

7. The Royal College of Obstetricians and Gynaecologists. Preventing Entry related gynaecological laparoscopic injury. RCOG Green top guideline No. 49. May 2008. Available from: http://www.rcog.org. uk/resources/Public/pdf/green_top49_PreventingLaparoscopicInjury. pdf

8. Garry R (1994) The evolution of a technique for laparoscopic hysterectomy: laparoscopic-assisted Doderlein's hysterectomy. Gynaecol Endosc 3:123-128
9. El Bishry G, Phillips G (2006) A new technique for dissecting the bladder laparoscopically. Gynaecol Surg 3:259-263

10. National Institute for Health and Clinical Excellence. Laparoscopic techniques for hysterectomy. Interventional procedure guidance 239. November 2007. Available from: http://www.nice.org.uk/ nicemedia/pdf/IPG239Guidance.pdf

11. Chapron C, Fauconnier A, Goffinet F, Bréart G, Dubuisson JB (2002) Laparoscopic surgery is not inherently dangerous for patients presenting with benign gynaecologic pathology. Results of a meta-analysis. Hum Reprod 17:1334-1342

12. Ou CS, Beadle E, Presthus J, Smith M (1994) A multicenter review of 839 laparoscopic-assisted vaginal hysterectomies. J Am Assoc Gynecol Laparosc 1:417-422

13. Hulka JF, Levy BS, Parker WH, Phillips JM (1997) Laparoscopicassisted vaginal hysterectomy: American Association of Gynecologists' 1995 membership survey. J Am Assoc Gynecol Laparosc $4: 167-171$

14. Weingertner A, Rodriguez B, Ziane A, Gibon E, Thoma V, Osario $\mathrm{F}$ et al (2008) The use of JJ stent in the management of deep endometriosis lesion, affecting or potentially affecting the ureter: a review of our practice. BJOG 115:1159-1164

15. Jansen FW, Kapiteyn K, Trimbos-Kemper T, Hermans J, Trimbos JB (1997) Complications of laparoscopy: a prospective multicentre observational study. BJOG 104:595-600

16. Preston JM (2000) Iatrogenic ureteric injury: common medicolegal pitfalls. BJU 86(3):313-317 